\title{
Correction to: Weak faults at megathrust plate boundary respond to tidal stress
}

\author{
Takashi Tonegawa ${ }^{1 *}$, Toshinori Kimura' ${ }^{1}$ Kazuya Shiraishi', Suguru Yabe ${ }^{2}$, Yoshio Fukao ${ }^{1}$, Eiichiro Araki ${ }^{1}$, \\ Masataka Kinoshita ${ }^{3}$, Yoshinori Sanada ${ }^{1}$, Seiichi Miura', Yasuyuki Nakamura ${ }^{1}$ and Shuichi Kodaira ${ }^{1}$
}

\section{Correction to: Earth Planets Space 73, 89 (2021) https://doi.org/10.1186/s40623-021-01414-3}

After publication of this article (Tonegawa et al. 1), it is noted that the given name and family name of the 8th author were interchanged. The correct name should be Yoshinori Sanada.

The author name has, therefore, been revised in this Correction.

The original article has been updated as well.

\section{Author details}

'Japan Agency for Marine-Earth Science and Technology (JAMSTEC), 2-15, Natsushima-cho, Yokosuka 237-0061, Japan. ${ }^{2}$ National Institute of Advanced Industrial Science and Technology, 1-1-1, Umezono, Tsukuba, Ibaraki
305-8560, Japan. ${ }^{3}$ The University of Tokyo, 1-1-1, Yayoi, Bunkyo 113-0032, Japan.

Published online: 13 May 2021

\section{Reference}

Tonegawa T, Kimura T, Shiraishi K et al (2021) Weak faults at megathrust plate boundary respond to tidal stress. Earth Planets Space 73:89. https://doi. org/10.1186/s40623-021-01414-3

\section{Publisher's Note}

Springer Nature remains neutral with regard to jurisdictional claims in published maps and institutional affiliations. the source, provide a link to the Creative Commons licence, and indicate if changes were made. The images or other third party material in this article are included in the article's Creative Commons licence, unless indicated otherwise in a credit line to the material. If material is not included in the article's Creative Commons licence and your intended use is not permitted by statutory regulation or exceeds the permitted use, you will need to obtain permission directly from the copyright holder. To view a copy of this licence, visit http://creativecommons.org/licenses/by/4.0/. 